\section{Ground vibrations level characterization through the geological strength index (GSI)}

The Mining-Geology-Petroleum Engineering Bulletin UDC: $553.5: 622.2$

DOI: 10.17794/rgn.2017.1.1

Original scientific paper

\author{
Josip Mesec'; Stjepan Strelec'; Denis Težak ${ }^{1}$ \\ ${ }^{*}$ University of Zagreb, Geotechnical Faculty in Varaždin, Hallerova 7, 42000 Varaždin, Croatia
}

\begin{abstract}
This paper analyses the results of trial, construction and quarry blasting, carried out in sediment rock deposits, mainly limestone and dolomite, at different locations in the Republic of Croatia. The division of the three test groups was based on the lithology changes and GSI values of the rock units at these locations. The peak particle velocity measurements with 246 recorded events, was conducted during a long period of six years. Based on the results of seismic measurements, the empirical relationships between peak particle velocity and scaled distance were established for each group. In order to establish a useful relationship between peak particle velocity and scaled distance, simple regression analysis was conducted with the Blastware software program from Instantel. The results of this study can be used to characterize ground vibration levels to the environment, through the geological strength index (GSI).
\end{abstract}

\title{
Keywords
}

Ground vibrations, Blasting, Geological strength index (GSI), Peak particle velocity

\section{Introduction}

The vibration generated by construction or quarry blasting may have an adverse impact on the environment. The vibration effects vary from human annoying disturbances to structural damage. Scientists and experts in this area agree that the level of excited ground and structure vibrations depends on blasting technology, explosive type and weight, delay-timing variations, site geology, scaled distance, parameters of waves propagating at a site, susceptibility ratings of adjacent and remote structures, and other factors. However, the prediction of particle velocity has a great importance in the minimization of the environmental complaints. Estimating the particle velocity and the other components of ground vibration are very useful in blast design (Downing, 1985; Kahriman, 2004; Mesec, 2005).

Conducted blasting at the different locations in the Republic of Croatia has resulted in the determination of ground vibrations on the points where the seismographs were placed. The peak particle velocities on these locations were measured during the bench blast optimization studies, the constructions and bench blasting over the period of six years. Monitoring stations were at a distance between 2.40 and $379 \mathrm{~m}$ from blasts. For monitoring, Instantel Minimate Series II vibration monitors were used most often, and for analysis, Instantel Blastware Version 8.0 software program were used (Instantel Inc., 2004).

Corresponding author: Josip Mesec jmesec@gfv.hr
In blasting operations, $A N F O$ were used as explosives and NONEL detonators were used as initiation systems. Hole lengths were between 4.5 and $27 \mathrm{~m}$, drill hole diameters were 76 to $89 \mathrm{~mm}$, and charge weight per delay were from 0.9 to $272 \mathrm{~kg}$.Finally, the empirical relationship between peak particle velocity and scaled distance were established for each of the three rock mass groups based on the results of seismic measurements (Mesec et al., 2010).

Based on a series of blast and seismic measurements, utilizing SD criteria, the dependence of peak particle velocity on scaled distance at the given location was empirically determined,

$$
P P V=K \cdot(S D)^{-n}
$$

Where:

$K$ and $\mathrm{n}-$ site factors, $S D$ - scaled distance $(\mathrm{m} / \mathrm{kg})$.

Scaled distance is the parameter which is related to the level of vibrations from the blast,

$$
S D=D /(C W)^{1 / 2}
$$

Where:

$D$ - distance (m),

$C W$ - charge weight of explosives detonated per delay $(\mathrm{kg})$.

In this relationship, as distance increases or the amount of explosives decreases, the scaled distance increases. As scaled distance increases the vibrations will decrease (Siskind, 1980). 
Table 1. Estimate of Geological Strength Index (GSI) (Hoek and Brown, 1997)

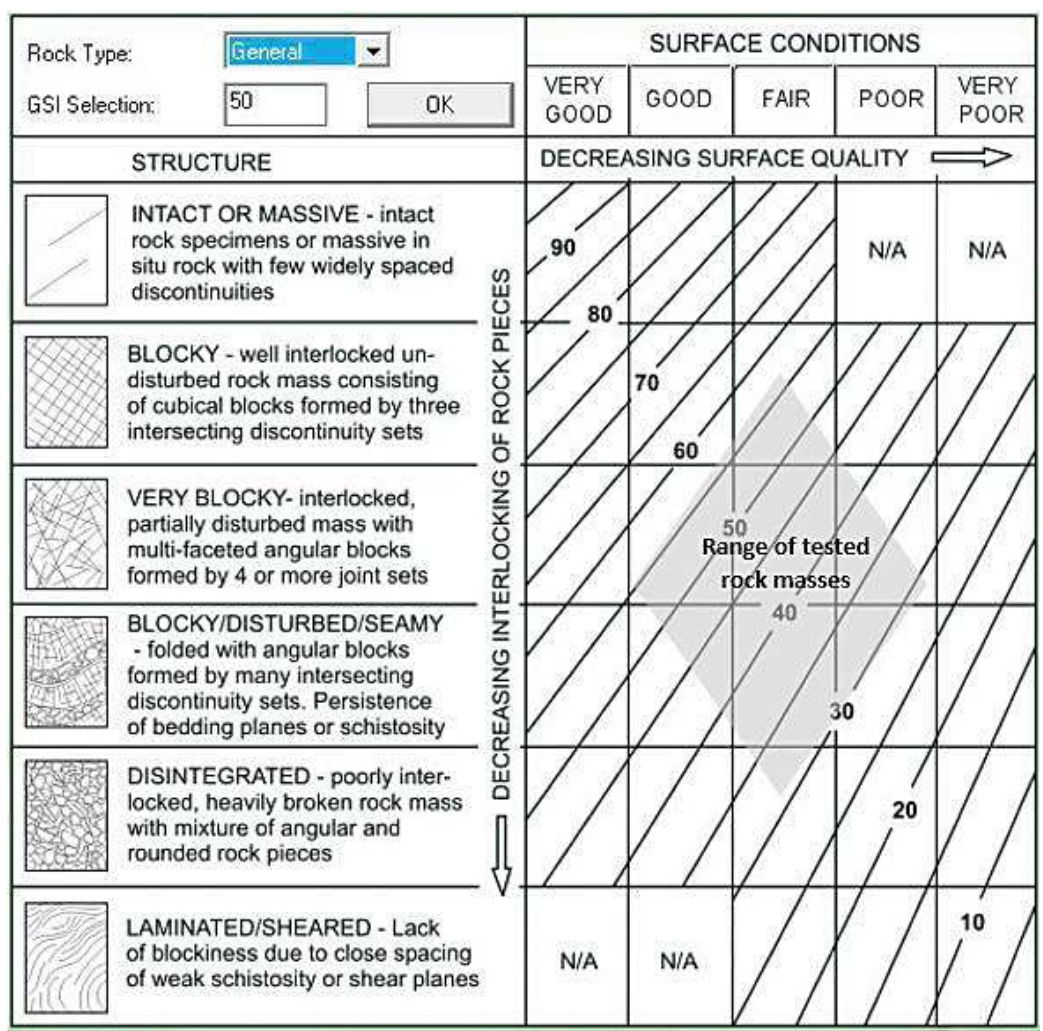

This paper also includes the results of measurements from the basic tectonic system at the different rock units. The measurements of the basic tectonic system have resulted in the determination of the geological strength index $(G S I)$, as defined by Hoek (Hoek, 1995) according to RMR classification by Bieniawski ZT (Bieniawski, 1989) and $Q$ classification by Barton NR, Lien $\mathrm{R}$ and Lunde J (Barton, Lien and Lunde, 1974). The GSI system is the only rock mass classification system that is directly linked to engineering parameters such as MohrCoulomb, Hoek-Brown strength parameters or rock mass modulus. The most important component of the Hoek - Brown system for rock masses with range of tested rock masses is accomplished through the geological strength index (GSI) that is defined in Table 1.

Rock mass characterization has an important role, not only to define a conceptual model of the site geology, but also for the quantification needed for analyses "to ensure that the idealization (for modelling) does not misinterpret actuality" (Knill, 2003). If it is carried out in conjunction with numerical modelling, rock mass characterization presents the prospect of a far better understanding of the mechanics of rock mass behaviour (Chandler et al., 2004).

The GSI system has considerable potential for use in rock engineering because it permits many characteristics of a rock mass to be quantified, thereby enhancing geological logic and reducing engineering uncertainty. Its use allows the influence of variables, which make up a rock mass, to be assessed and thus the behaviour of rock masses to be explained more clearly. One of the advantages of the GSI is that the geological reasoning it embodies allows adjustments of its ratings to cover a wide range of rock masses and conditions, but it also allows us to understand the limits of its application. (Marions and Hoek, 2007)

\section{Rock mass test groups}

According to the GSI values, investigations and measurements are conducted at different locations in the Republic of Croatia, see Figure 1.

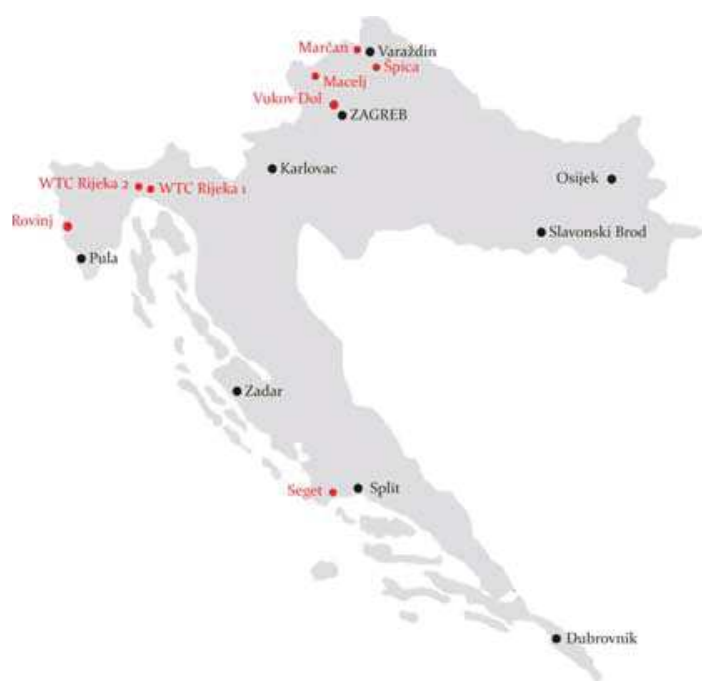

Figure 1. Research locations in Republic of Croatia 
Table 2. Rock mass test groups

\begin{tabular}{|l|l|l|l|c|}
\hline Group & Location & Type of location & Type of rock mass & GSI value \\
\hline I & Macelj & notch at the border crossing & sandstone & 30 \\
& Marčan & aggregate quarry & limestone & 32 \\
& Seget & aggregate quarry & limestone & 37 \\
\hline II & WTC Rijeka 2 & construction pit & limestone & 43 \\
& Rovinj & construction pit & dolomite limestone & 45 \\
& Vukov Dol & aggregate quarry & marbleized limestone & 50 \\
\hline III & Shica & aggregate quarry & dolomite limestone & 52 \\
& WTC Rijeka 1 & construction pit & limestone & 55 \\
\hline
\end{tabular}

The division of the three test groups was based on the lithology changes and GSI values of the rock units at these locations, see Table 2.

\section{Blasts and the ground vibrations measuring, measured and calculated values for all test groups}

Following the conducted research and the verification of obtained results, the dependence of peak particle ve- locity on the scaled distances, $P P V=K \cdot(S D)^{-n}$ has been defined at other locations, and for each rock mass test group as well, see Table 3. The number of recorded events for each location was at least 30 , so that enough data determined that dependence.

Based on the data stated in Table 3, $P P V-S D$ diagrams were drawn as summaries for all three groups, see Figure 2.

Figure 3 shows the mine field in construction pit, research location Rovinj.

Table 3. Measured and calculated values, all locations

\begin{tabular}{|c|c|c|c|c|c|c|c|}
\hline Group & $\begin{array}{l}\text { The number } \\
\text { of recorded } \\
\text { events }\end{array}$ & Location & $\begin{array}{c}G S I \\
\text { value }\end{array}$ & $\begin{array}{l}\text { Oscillation velocity } \\
\text { relationship PPV, } \\
(\mathrm{mm} / \mathrm{s})\end{array}$ & r value & $\begin{array}{l}\text { Oscillation velocity } \\
\text { groups relationship }\end{array}$ & $\begin{array}{l}\text { Group } \\
\text { r value }\end{array}$ \\
\hline \multirow{3}{*}{ I } & \multirow{3}{*}{90} & Macelj & 30 & $\mathrm{PPV}=4331(S D)^{-1.81}$ & 0.89 & \multirow{3}{*}{$\mathrm{PPV}=2023(S D)^{-1.50}$} & \multirow{3}{*}{0.83} \\
\hline & & Marčan & 32 & $\mathrm{PPV}=138(S D)^{-0.63}$ & 0.92 & & \\
\hline & & Seget & 37 & $\mathrm{PPV}=697(S D)^{-1.20}$ & 0.89 & & \\
\hline \multirow{2}{*}{ II } & \multirow{2}{*}{64} & WTC Rijeka 2 & 43 & $\mathrm{PPV}=809(S D)^{-1.52}$ & 0.89 & \multirow{2}{*}{$\mathrm{PPV}=884(S D)^{-1.47}$} & \multirow{2}{*}{0.86} \\
\hline & & Rovinj & 45 & $\mathrm{PPV}=940(S D)^{-1.43}$ & 0.94 & & \\
\hline \multirow{3}{*}{ III } & \multirow{3}{*}{92} & Vukov Dol & 50 & $\mathrm{PPV}=508(S D)^{-1.37}$ & 0.89 & \multirow{3}{*}{$\mathrm{PPV}=349(S D)^{-1.38}$} & \multirow{3}{*}{0.86} \\
\hline & & Špica & 52 & $\mathrm{PPV}=1204(S D)^{-1.94}$ & 0.83 & & \\
\hline & & WTC Rijeka 1 & 55 & $\mathrm{PPV}=155(S D)^{-1.11}$ & 0.84 & & \\
\hline
\end{tabular}

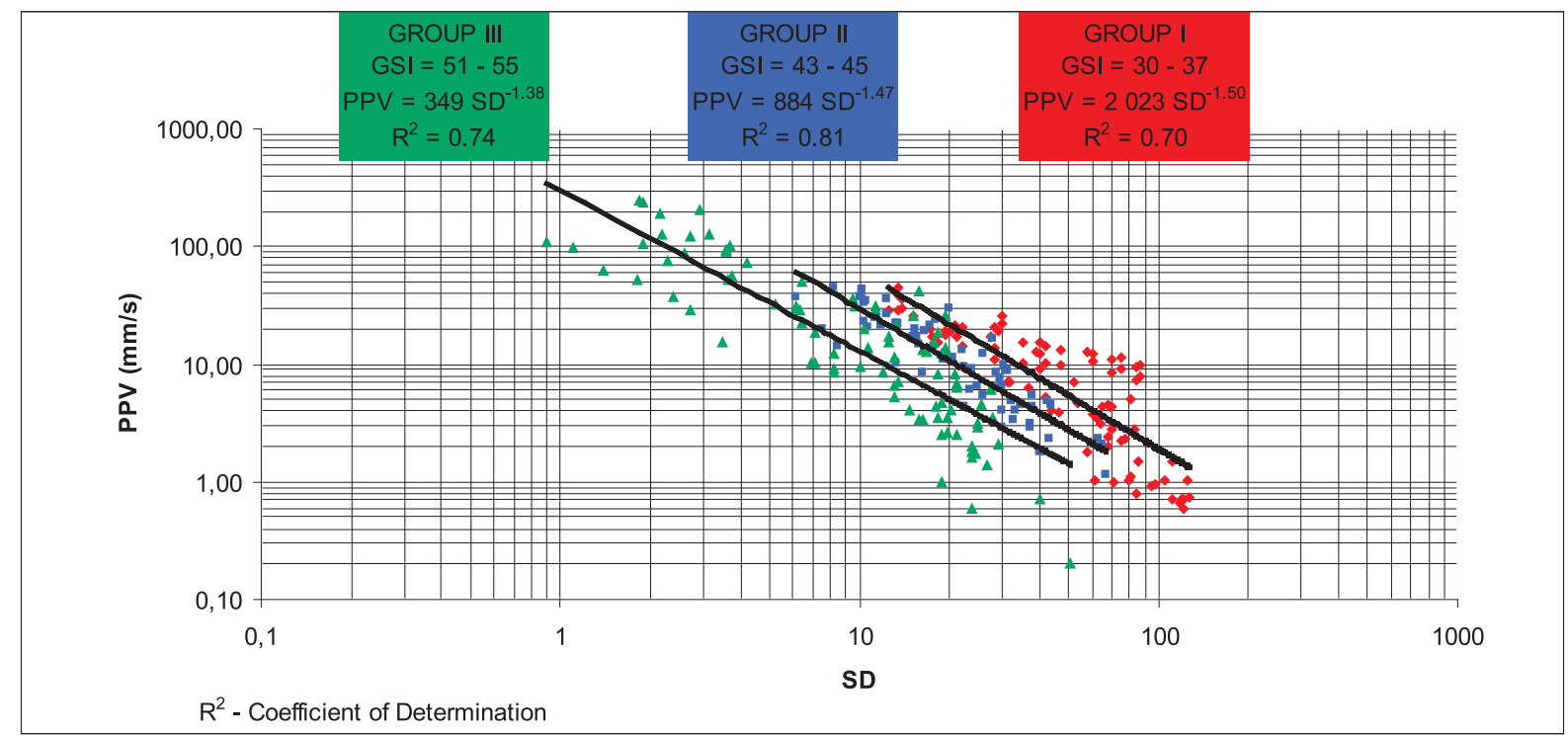

Figure 2. Dependences of peak particle velocity $(P P V)$ on scaled distance $(S D)$ 


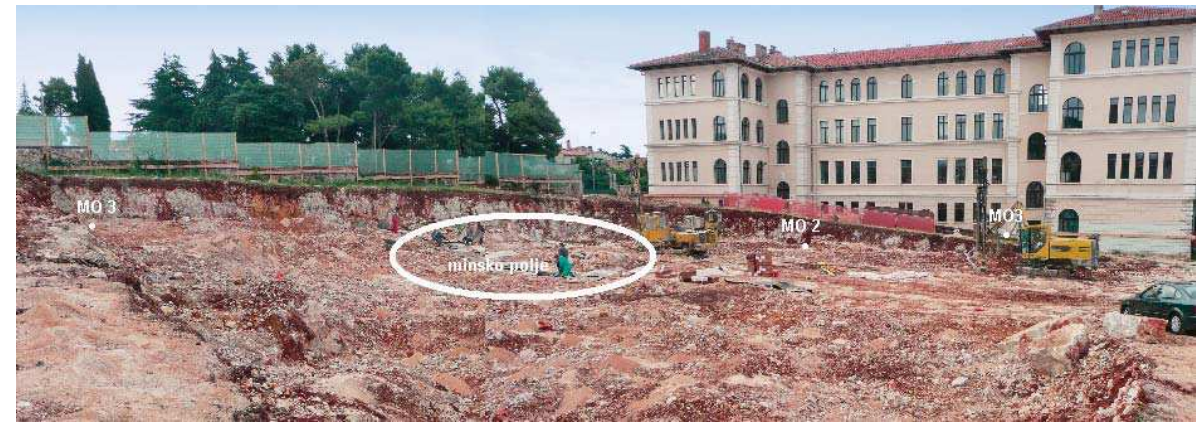

Figure 3. Mine field in construction pit, research location Rovinj

\section{Scaled distance analysis}

In order to establish a useful relationship between peak particle velocity and scaled distance, simple re-

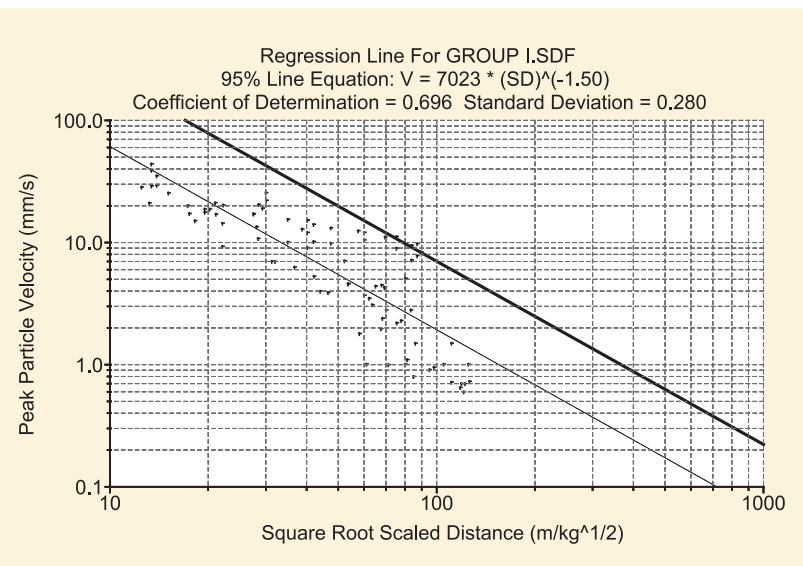

Figure 4. GROUP I: Regression and Line of $95 \%$ Confidence

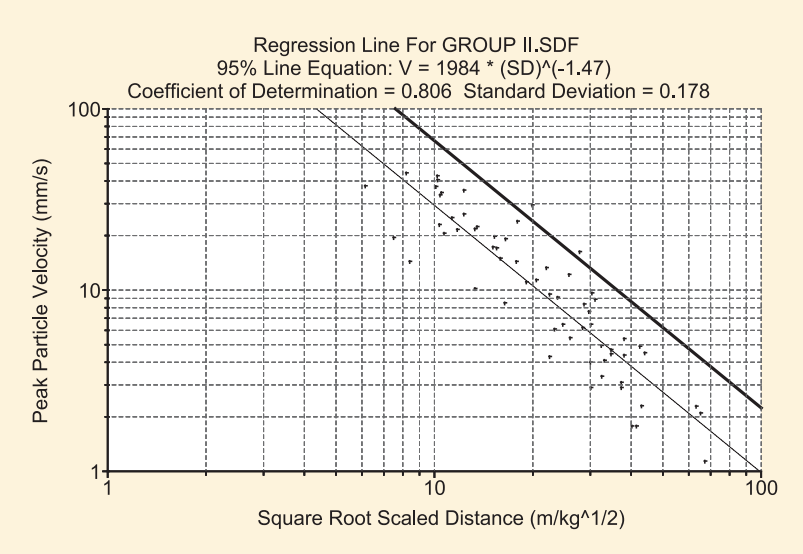

Figure 5. GROUP II: Regression and Line of $95 \%$ Confidence

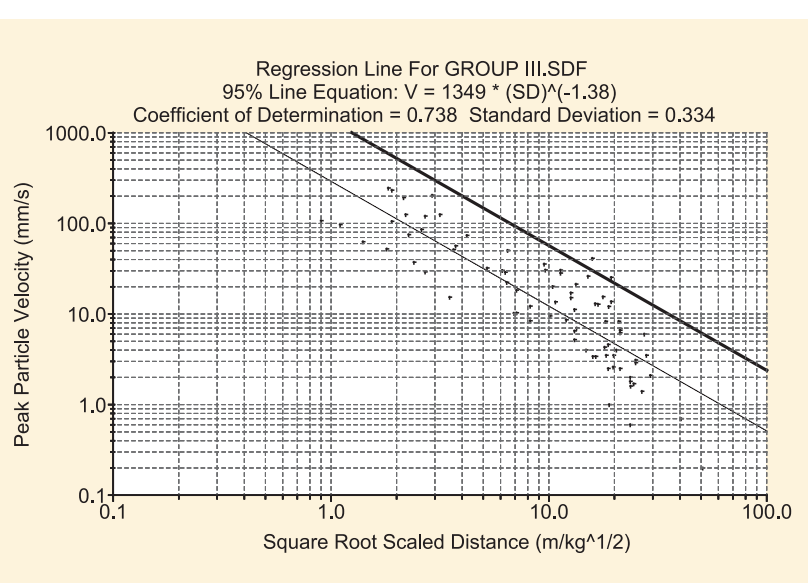

Figure 6. GROUP III: Regression and Line of $95 \%$ Confidence

gression analysis was conducted with the Blastware software program from Instantel, for each of the three groups separately (Mesec et al., 2010). Scaled distance analysis is a useful tool for quick and confident calculation of the maximum charge weight per delay and the minimum safe structure distance for a specific blast site. As a result, each group is given $95 \%$ confidence equations, coefficients of determination and standard deviation for the prediction of PPV on controlled blasting activities, see Figures 4, 5 and $\mathbf{6}$.

The scaled distance analysis is summarized in Table 4.

\section{Conclusions}

The results of this paper may be used for some basic vibration prediction and trial blast design starting points, which should be made prior to construction and quarry blasting. As stated in the introduction, the GSI system has considerable potential for use in rock engineering because it permits many characteristics of a rock mass to

Table 4. Scaled distance analysis results

\begin{tabular}{|l|c|l|c|l|c|c|}
\hline Group & GSI & $\begin{array}{l}\mathbf{5 0} \% \text { Mean } \\
\text { line Equation }\end{array}$ & r Value & $\begin{array}{l}\text { 95\% Confidence } \\
\text { lin Equation }\end{array}$ & $\begin{array}{c}\mathbf{R}^{2} \text {, Coefficient } \\
\text { of Determination }\end{array}$ & $\begin{array}{c}\text { Standard } \\
\text { Deviation }\end{array}$ \\
\hline I & $30-37$ & PPV $=2023(S D)^{-1.50}$ & 0.83 & PPV $=7023(S D)^{-1.50}$ & 0.70 & 0.280 \\
\hline II & $43-45$ & PPV $=884(S D)^{-1.47}$ & 0.90 & PPV $=1984(S D)^{-1.47}$ & 0.81 & 0.178 \\
\hline III & $50-55$ & PPV $=349(S D)^{-1.38}$ & 0.86 & PPV $=1349(S D)^{-1.38}$ & 0.74 & 0.334 \\
\hline
\end{tabular}


be quantified, thereby enhancing geological logic and reducing engineering uncertainty.

The division of the three test groups was based on the lithology changes and GSI values of the rock units on the investigated locations. The peak particle velocity measurements with 246 recorded events, were conducted over a long period of six years. The empirical relationship with good correlation has been established between peak particle velocity and scaled distance for each rock mass test group as well. Using these relationships, practical charts should be prepared for various charge levels and distances to control blasting for each engineering geological type of sediment rock mass, GSI range of 30 to 55. That is the most common type of rock mass in the Republic of Croatia.Research clearly shows that the ground vibration levels are much higher in the weaker rock masses, respectively to those which have a lower GSI.

This mentioned assertion has a particular importance when the blasting is carried out in urban areas. In these cases, cooperation between the engineering geologist and the mining engineer who designs and performs blasting is more than necessary. Blasting will be carried out successfully if the harmful effects of mining are reduced to allowable limits.For example, according to the value of scaled distance $\mathrm{SD}=20$, the maximum of peak particle velocity varies from $5 \mathrm{~mm} / \mathrm{s}$ (group I, GSI $=51$ to 55 ) to the $22 \mathrm{~mm} / \mathrm{s}$ (group III, GSI = 30 to 37), Figure 2. If that relationship in practice is replaced with specific values, e.g., comes out for a distance of 10 meters the endangered object from minefield, charge weight of 0.7 $\mathrm{kg}$ per delay would cause the ground vibrations in the mentioned range of 5 to $22 \mathrm{~mm} / \mathrm{s}$. The significance of such specified range of the ground vibration level is best reflected in comparison with one of the world-recognized standards, for example DIN standards 4150 .

However, it should be taken into consideration that these relationships established just for the prediction of peak particle velocity gives incomplete results because of other geological and blast effects. To support the reliability of this study, accompanied by the maximum measured peak particle velocities and its principal frequencies should be included. In this case, the results of this study can be used to characterize ground vibration levels to the environment, through the geological strength index (GSI).

\section{References}

Barton, N.R., Lien, R. and Lunde, J. (1974): Engineering classification of rock masses for the design of tunnel support, Journal of Rock Mechanics, 6, 189-223.

Bieniawski, Z.T. (1989): Engineering rock mass classifications: a complete manual for engineers and geologists in mining, civil and petroleum engineering, A Wiley- Interscience Publications.

Chandler RJ, de Freitas MH, Marinos P (2004): Geotechnical characterization of soils and rocks: a geological perspective. In: Proceedings of the Advances in Geotechnical Engineering: The Skempton Conference. Vol 1. London: Thomas Telford, 67-102.

Chandler RJ, de Freitas MH, Marinos P (2004): Geotechnical characterization of soils and rocks: a geological perspective. In: Proceedings of the Advances in Geotechnical Engineering: The Skempton Conference. Vol 1. London: Thomas Telford, 67-102.

Downing CH. (1985): Blast vibration monitoring and control. Englewood Cliffs, NJ: Pretince-Hall.

Hoek, E. (1995): Strength of rock \& rock masses. ISRM News Journal, 2 4-17.

Instantel Inc. Blastware (2004): Operator Manual,Ottawa.

Kahriman, A. (2004): Analysis of parameters of ground vibration produced from bench blasting at the limestone quarry. Soil Dynamics and Earthquake Engineering, 24 887-892.

Knill, J. (2003): Core values (first Hans-Closs lecture). Bull Eng Geol Env 62:1-34.

Marinos, P., V. Marinos, and E. Hoek. (2007): "Geological Strength Index (GSI). A characterization tool for assessing engineering properties for rock masses.", Proceedings International Workshop on Rock Mass Classification for Underground Mining, 87-94.

Mesec, J., Kovač, I., Soldo B. (2010): Estimation particle velocity on the basis of the blast event measurements at the different rock units. Journal: Soil Dynamics and Earthquake Engineering. Vol. 30, 1004-1009.

Mesec, J. (2005): Dependence of ground vibrations on the engineering geological rock mass properties caused by blasting in sediment rock deposits. Doctoral dissertation. University in Zagreb, Faculty of Mining, Geology and Petroleum Engineering. Zagreb

Siskind, D. E. (1980): Structure response and damage produced by ground vibration from surface mine blasting [R], U.S. Bureau of Mines. 